\title{
CONCEITO DE SUJEITO KANTIANO E O PROJETO DE DWORKIN NO JUSTIÇA PARA OURIÇOS
}

\section{Saulo Monteiro Martinho de Matos* Lorena da Silva Bulhões Costa**}

Resumo: Este trabalho discute críticas contemporâneas à fundamentação kantiana da dignidade humana. A partir da obra "Justiça para Ouriços", o estudo discute uma possível resposta a essas críticas por meio da tese da conexão entre ética e moral. Primeiro, o texto irá apresentar o conceito de dignidade humana na filosofia moral de Immanuel Kant (imperativo categórico). Após, as críticas contemporâneas ao individualismo normativo serão explicitadas a partir de Nussbaum. Por fim, o modelo de dignidade proposto por Dworkin será apresentado como possível caminho. Como conclusão, a reformulação de Dworkin do conceito kantiano ainda está sujeita aos problemas do individualismo normativo.

Palavras-chave: Kant; Dworkin; Dignidade humana; Individualismo; Nussbaum.

\section{KANTIAN CONCEPT OF SUBJECT AND DWORKIN'S PROJECT IN JUSTICE FOR HEDGEHOGS}

\begin{abstract}
This article analyzes contemporary critiques concerning Kantian foundation of human dignity. Based on Dworkin's "Justice for Hedgehogs", this study discusses a possible answer to that challenge through the thesis of necessary connection between ethics and morality. First, Kant's human dignity will be presented in the context of his categorical imperative. Second, contemporary critiques to normative individualism will be debated on the basis of recent works of Martha Nussbaum. Finally, Dworkin's human dignity will be presented as possible way out. It concludes that Dworkin's reformulation of Kant's human dignity cannot give a final answer to contemporary critiques on normative individualism.
\end{abstract}

Keywords: Kant; Dworkin; Dignity; Normative individualism; Nussbaum.

\section{INTRODUÇÃO}

\footnotetext{
* Professor Adjunto de Ética, Hermenêutica Jurídica e Teoria do Direito da Faculdade de Direito da Universidade Federal do Pará. Professor Permanente do Programa de Pós-graduação em Direito da Universidade Federal do Pará. Coordenador do Grupo de Pesquisa (CNPq) Teorias Normativas do Direito. Endereço: Instituto de Ciências Jurídicas. Programa de Pós-graduação em Direito. R. Augusto Corrêa, nº 01. CEP: 66075-110. Belém/PA. Endereço eletrônico: saulomdematos@gmail.com.

** Mestranda em Direitos Humanos da Universidade Federal do Pará. Graduada em Direito pela Estácio Castanhal. Bacharelanda em Filosofia pelo Centro Universitário Internacional (UNINTER). Membro do Grupo de Pesquisa (CNPq) Teorias Normativas do Direito. Bolsista Capes/CNPQ. Endereço eletrônico: lorenabulhoescosta@hotmail,com.
} 
A dignidade humana ou, para fins deste estudo apenas "dignidade", é amiúde tratada como um valor absoluto. ${ }^{2}$ Comumente, é dito que a dignidade é necessária, incondicional, inviolável ou incomensurável. Esta forma de pensar é parte não só do discurso filosófico, mas, outrossim, do discurso jurídico e político do nosso tempo. Nesse sentido, uma premissa amplamente aceita com relação à dignidade humana é a sua indisponibilidade, a dizer, a ideia de que a dignidade é absoluta, pertencente a todo ser humano qua ser humano e válida independentemente de considerações temporais ou espaciais.

$\mathrm{Na}$ seara do discurso jurídico, a ideia de dignidade humana passa a ser de extrema importância para o controle das instituições sociais após a catástrofe do movimento fascista do último século. Dessa forma, através do valor da dignidade, direitos jurídicos passaram a ser justificados como indisponíveis, ou seja, independentes de positivação, invioláveis e incomensuráveis. Hodiernamente, compreende-se a dignidade, normalmente, com referência a Kant ou Aquino, como uma qualidade ou propriedade necessária a todo ser humano, intrínseca à sua natureza, da qual um direito ou pretensão a um tratamento especial pode ser justificado e, em alguns casos, judicializado. Dessa forma é como, e.g., o artigo primeiro da Lei Fundamental (Grundgesetz) da Alemanha de 1949 é normalmente compreendido: “A dignidade do ser humano é intocável (unantastbar). Respeitá-la e protegê-la é obrigação de todo Poder estatal" (trad. nossa). Todos os citados elementos de independência, indisponibilidade e incomensurabilidade da dignidade humana e sua relação com os direitos fundamentais foram desenvolvidos ao longo da jurisprudência do Tribunal Constitucional Alemão desde a década de 50 do século passado. ${ }^{3}$

Em que pese a importância desse conceito para a filosofia moral moderna, é possível observar uma tendência teórica de considerar a dignidade como um conceito extremamente indeterminado, que deve ser evitado no âmbito do discurso prático. É nesse contexto que a dogmática jurídica, acima citada, busca, com apelo a concepções teóricas específicas, em especial a kantiana, defender um determinado contorno como moldura para o conteúdo desse conceito, a fim de que ele possa cumprir a sua função de limitação das arbitrariedades das instituições sociais. ${ }^{4}$

\footnotetext{
2 "Valor" está sendo utilizado, aqui, no sentido de proposições ou razões substanciais (all things considered) na esteira de DWORKIN (2011) e GREENBERG (2004).

${ }^{3}$ Acerca disso: BRUGGER, 1999, pp. 253-84.

${ }^{4}$ A dogmatização jurídica, para fins deste estudo, consiste na prática de pressupor que todo conceito jurídico, pelo simples fato de ter sido incorporado a um texto legislativo, traz consigo uma concepção bem definida a ser
} 
No contexto do uso do conceito de dignidade humana na prática judicial e, portanto, desse processo de dogmatização da dignidade, MacCrudden (2008, p. 265) identificou três dimensões essenciais da dignidade humana: (a) uma dimensão ontológica, que compreende o valor e o significado do ser humano para fins, por exemplo, de direito à vida; (b) uma dimensão relacional, a dizer, quais formas de tratamento jurídico não correspondem ao respeito ao valor do ser humano; e, por fim, (c) a relação institucional entre cidadão e Estado, a qual compreende as possíveis interferências injustificadas nas liberdades fundamentais através do aparato coercitivo do Governo. Cada uma dessas dimensões pode estar relacionada a uma violação específica à dignidade humana.

Para que essa forma argumentativa possa, de fato, vir a funcionar, em especial em relação à primeira dimensão, MacCrudden (2008) considera que o trabalho de Immanuel Kant é decisivo. Pois, ao separar conhecimento racional e religioso, o fundamento para a dignidade em Kant (2009) passou a ser a razão. O ser racional adquiriu valor intrínseco e absoluto a partir da autonomia, ou seja, da capacidade de obediência à lei moral.

Não obstante a sua possível utilização dogmática, a argumentação desse conceito a partir dos moldes kantianos, hodiernamente, é controversa. A principal crítica a essa concepção consiste na ideia de que o sujeito Kantiano seria extremamente racionalista, alheio a projetos pessoais e ao autointeresse, o que estaria longe do ser humano real, tornando-o uma mera ficção. Nesse sentido, como modelo alternativo, as teorias marxianas seriam capazes de conferir uma maior concretude ao sujeito da dignidade (SARMENTO, 2016).

Isso não significa, contudo, que não existam reinterpretações mais ou menos fiéis à teoria kantiana original, que buscam defendê-la. Recentemente uma dessas releituras foi proposta por Dworkin (2011) em seu livro Justice for Hedgehogs, traduzido para o português brasileiro como A raposa e o porco-espinho (2014).

$\mathrm{Na}$ citada obra, o autor defende a dignidade como valor fundante do discurso prático. Nessa toada, a dignidade humana é passível de ser compreendida, entre outros, no âmbito da ética, moral ou moralidade pessoal e política ou moralidade institucional.

$\mathrm{Na}$ ética, a dignidade se relaciona com a concepção de vida digna para o sujeito. A moral ou a moralidade pessoal, por seu turno, compreende as relações entre, pelo menos, dois sujeitos e a quais ações um sujeito é obrigado para com o outro em razão do reconhecimento

aplicada à solução dos conflitos judiciais, ignorando o desacordo teórico existente em conceitos como esse (DWORKIN, 1986, p. 225). 
deste como pessoa (moral) e da sua dignidade. Isto é, a moral compreende as minhas obrigações morais em relação a uma outra pessoa em razão da sua dignidade.

Já a política, ou mais precisamente, a moralidade institucional, representa o domínio dos direitos de comunidade política ante um indivíduo. Significa discutir quais ações podem ser exigidas dos indivíduos por uma coletividade com pretensão de autoridade soberana sem ferir a sua dignidade.

Em síntese, a ética compreende o espaço do "eu" (primeira pessoa do singular); a moral, do "tu" (segunda pessoa do singular); e a política discute a esfera do "nós" (primeira pessoa do plural). O direito é parte da política, porque a linguagem de direitos jurídicos serve para legitimar as ações que uma comunidade política ou Governo pode exigir de seus membros ou indivíduos. ${ }^{5}$

Essa ideia de Dworkin (2011) tem como ponto basilar uma noção kantiana de moral e é trabalhada a partir dos conceitos de humanidade e autonomia, pressupondo uma leitura da moralidade kantiana que seja compatível com o seu projeto ético. Este estudo, portanto, tem por objetivo central discutir em que medida o modelo kantiano de fundamentação da dignidade, tal qual proposto por Dworkin, consegue responder às críticas ao modelo tradicionalmente atribuído a Kant. Tais críticas estão centradas, sobretudo, no pressuposto metafísico da filosofia moral kantiana. ${ }^{6}$ Com base nessa releitura, faz-se o seguinte questionamento: a reformulação do conceito de valor objetivo do ser humano, feita por Dworkin, é capaz de superar as críticas à noção kantiana de dignidade?

É importante deixar claro, a partir da pergunta ora colocada, que o estudo não está interessado em discutir a origem histórica, o significado e a aplicação do conceito de dignidade, mas, sim, exclusivamente a dimensão da fundamentação.

A metodologia da presente pesquisa tem como método de abordagem o dedutivo, considerando o escopo de, a partir do conceito geral de dignidade, analisar duas concepções específicas, quais sejam, a de Kant (2009) e de Dworkin (2011). O método de procedimento será o estrutural, pois artigo terá como foco a reconstrução de um modelo de dignidade a partir da teoria de Dworkin (2011). A técnica de pesquisa será a bibliográfica e terá como

\footnotetext{
${ }^{5}$ Direitos jurídicos podem, no entanto, ser diferenciados de direitos políticos: "Direitos jurídicos são aqueles que as pessoas estão autorizadas a exigir por meio de um pedido, sem outra intervenção legislativa, em instituições adjudicativas, as quais orientam o poder executivo de delegados ou policiais." (DWORKIN, 2011, p. 406) (trad. nossa). Acerca disso: (ELEFTHERIADIS, 2008).

${ }^{6}$ Metafísica significa, aqui, então, uma ontologia ou doutrina que determina as características fundamentais que todo ser tem e não pode deixar de ter (ABBAGNANO, 2007, p. 768).
} 
foco as seções 2 e 3 da Fundamentação da Metafísica dos Costumes (2009) e os capítulos 9 e 11 do Justiça para Ouriços. Também, serão trabalhados, no caso de Kant (2009), comentadores que tratam da questão da dignidade humana no iluminista. Dada a amplitude das críticas ao projeto kantiano, será trabalhada uma objeção específica: a de que o sujeito kantiano seria impossível, vez que destituído de projetos pessoais e desejos empíricos. Para tanto serão trabalhadas as obras de Daniel Sarmento (2016), Luís Roberto Barroso (2012) e Martha Nussbaum (2013), considerando, no caso dessa última, a questão da ética do cuidado.

Como dito anteriormente, Kant (2009) é central na fundamentação filosófica do conceito de dignidade, e a sua teoria do valor absoluto dos seres humanos é central na cronologia desse conceito. Nisso justifica-se a adoção das suas ideias como referencial teórico. A teoria de Dworkin (2011), por outro lado, foi escolhida para o presente trabalho porque apresenta uma reconstrução da filosofia kantiana tendo como foco, justamente, a influência desta para a ideia de valor absoluto dos sujeitos que fica clara na obra Justiça para Ouriços.

Nessa toada, este trabalho apresentará a seguinte estrutura argumentativa: (a) delimitação do que Kant entende por dignidade; (b) apresentação da crítica ao sujeito kantiano; (c) apresentação do modo como a teoria de Dworkin argumenta a favor de uma ideia de valor objetivo da vida humana para, por fim, travar uma (d) discussão acerca das críticas ao conceito de valor absoluto em Kant ao projeto de Dworkin.

A conclusão do trabalho é no sentido de que, em que pese a proposta dworkiniana de fundamentação do conceito de dignidade possa ser vista como um caminho para compreensão desse conceito em um contexto não-metafísico, a ausência da preocupação de Dworkin com relação às condições sociais, às quais os indivíduos estão necessariamente vinculados, faz com que o seu modelo ainda esteja sujeito às críticas apresentadas ao modelo kantiano.

\section{A DIGNIDADE DO PONTO DE VISTA KANTIANO}

A noção de dignidade, em Kant, surge no seio da construção da sua ideia de lei moral. Esse conceito, em brevíssimo resumo, tem em seu cerne a noção de imperativo categórico e é um teste de princípios subjetivos do querer, ou seja, máximas, que o sujeito pretende tornar lei moral, válida para todos os seres racionais (KANT, 2009). 
Esse teste de máximas possui três passos principais ${ }^{7}$. No primeiro deles, a fórmula da lei universal, Kant (2009) buscará traçar a forma que a lei moral deve possuir, ou seja, a mera legislação universal. Nesse passo o sujeito racional tentará universalizar a sua máxima e torná-la válida para todos, sem que ela apresente nenhuma contradição.

O segundo passo, a fórmula da humanidade, é geralmente associado à ideia de dignidade. $\mathrm{O}$ foco dessa segunda etapa vai ser encontrar um fundamento para o imperativo categórico, tendo em vista que Kant excluiu desse âmbito tanto as consequências da ação, quanto os motivos baseados no mero interesse pessoal do sujeito. Por isso, ele irá argumentar que somente um fundamento com valor absoluto poderá ser permitido: a humanidade em todos os seres racionais (KANT, 2009).

Por vezes, Kant relaciona humanidade e dignidade e a fórmula em comento acaba sendo interpretada como a origem desse conceito no autor (FORMOSA, 2014). Na interpretação de Wood (2008) e de Formosa (2014), a humanidade refere-se à utilização de todas as capacidades dos seres racionais, independente de possuírem relação com a lei moral. É simplesmente uma racionalidade ampla.

Ao lado deste conceito figuram as noções de animalidade e personalidade, que são relevantes tanto para compreender a noção de autonomia e de dignidade, quanto para entender no que se pauta a crítica de Martha Nussbaum, a ser tratada no próximo tópico. Segundo Wood (2008) a animalidade tem como principal função a realização do que os instintos demandam e a personalidade diz respeito à capacidade de obedecer a lei moral e está ligada à noção de autonomia.

Mas o termo "dignidade" só aparece na última etapa do imperativo categórico: a fórmula da autonomia. ${ }^{8}$ Do conceito de "fim em si mesmo" presente na fórmula da humanidade, Kant deriva a noção de que todo ser racional deve ser visto como um legislador frente à lei moral e isso conduz à ideia de autonomia, que confere um valor absoluto ao homem (WEYNE, 2013).

O conceito de autonomia, tomado dessa forma, por sua vez, encontra raízes em Rousseau. O suíço, em seu Emílio e ao formular as bases para O Contrato Social, repensou a

\footnotetext{
7 Alguns autores, como Wood (2008), dividem o imperativo categórico em cinco fórmulas: fórmula da lei universal, fórmula da lei na natureza, fórmula da humanidade, fórmula da autonomia e fórmula do reinos dos fins. Aqui a divisão será tripartite: fórmula da lei universal, fórmula da humanidade e fórmula da autonomia.

${ }^{8}$ Por essa razão, há alguns autores que associam a dignidade, exclusivamente, à terceira formulação do imperativo categórico. Ver: PFORDTEN, 2009, p. 9-26.
} 
noção de liberdade negativa. Para Rousseau, enquanto o ser racional não pudesse se libertar do que mais tarde Kant chamaria de "leis da natureza", então ele não seria considerado propriamente livre. Esse conceito, portanto, está ligado ao de autolegislação (HONNETH, 2015).

Em Kant, a autonomia fundamenta a lei moral e, por não ser pautada em um mero desejo do sujeito e pode figurar, portanto, como uma base universal, válida para todos os seres racionais (WEYNE, 2013). Essa ideia de autonomia leva ao "reino dos fins", vez que considerando a noção de universalidade e retirando os fins pessoais dos sujeitos, então, é possível que se construa uma rede interligada de fins, que comporta tanto o sujeito como fim em si mesmo, quanto os fins que cada um escolheu para si.

A moralidade, portanto, irá encontrar a sua formulação máxima na ideia de que cada sujeito atua, ao mesmo tempo, como membro e como legislador universal, sujeitando-se apenas à sua vontade enquanto legisladora universal (KANT, 2009).

A dignidade, segundo Weyne (2013), surge como um corolário dessas ideias. É a noção de que, no reino dos fins, todos os indivíduos se autolegislam através da autonomia e respeitam os demais seres racionais como fins em si mesmos e, assim, todos possuem dignidade. Ou seja, os homens possuem um valor absoluto e, ao contrário das coisas, não podem ser trocados ou vendidos. O homem possui dignidade porque possui razão, ou seja, capacidade de determinar como deve agir e guiar a sua vontade frente ao mundo sensível (KANT, 2009).

\section{CRÍTICAS AO PROJETO DE KANT}

Apesar de possuir uma monumental influência histórica, a noção kantiana de dignidade enfrenta objeções, que são o foco deste tópico. Como será exposto na argumentação que se segue, as oposições a Kant surgem ainda dentro do idealismo alemão, movimento surgido a partir da publicação das ideias da Crítica da Razão Pura. Por conta da impossibilidade de tratar, portanto, de todas as contraposições à moralidade kantiana, este tópico irá abordar, especificamente, a crítica que é feita ao sujeito kantiano.

Barroso (2012) aponta as filosofias de Hume e Hegel como centrais, em termos de críticas, ao conceito de dignidade kantiano. A primeira reflete a suposta falta de 
comprometimento da ética kantiana com os desejos subjetivos do sujeito e a segunda o fato de que o sujeito kantiano não leva em consideração o contexto social no qual está inserido.

Barroso (2012) faz coro a estas objeções, argumentando que a razão, considerada isoladamente, como Kant aparentemente faz, não é capaz de controlar todo o comportamento humano. Assim, não é possível conceber um homem que não considere noções empíricas de bem e justo no momento das suas ações práticas. É impossível dissociar o comportamento humano desses tipos de influênicas como afetos, simpratias e ambições. Apesar disso, Barroso (2012) argumenta que algumas ideias que Kant formula, e aqui ele utiliza como referência principalmente a Fundamentação da Metafísica dos Costumes, tais como autonomia e imperativo categórico, são essenciais para o entendimento da dignidade.

Outro autor pátrio, que em seu estudo sobre dignidade, também formulou críticas ao projeto kantiano foi Daniel Sarmento (2016). A oposição do autor começa na descrição das trajetórias que o conceito de dignidade sofreu ao longo da história. Segundo Sarmento (2016) esse valor não nasce pronto e por isso ele propõe analisar as suas transformações, sendo a primeira delas a passagem de uma ideia hierarquizada do conceito de dignidade para uma noção mais universal e igualitária. Para tanto o imperativo categórico foi um raciocínio essencial.

A segunda fase trata da passagem do sujeito abstrato ao concreto. Nesse ponto, Sarmento (2016) narra que o surgimento do individualismo, em contraposição a uma noção mais coletiva de direitos dos indivíduos, foi adotado por Hobbes e Locke. Os interesses individuais justificavam instituições como o Estado. Nessas teorias, os sujeitos são desencarnados, desenraizados e abstratos. Não existe, portanto, qualquer preocupação com os sentimentos, os vínculos sociais e a corporalidade.

Isso, segundo Sarmento (2016), teve influência na ideia de dignidade de Kant. Esse conceito seria fundado unicamente na autonomia, determinando que os seres humanos são ligados somente aos ditames da razão. Nas palavras de Sarmento (2016, p. 43):

Trata-se de um ser humano abstrato, cuja liberdade estaria fora da natureza, não se sujeitando sequer às leis da causalidade. Uma pessoa que não existe e que, a rigor, sequer é possível. Como observou Emílio Santoro, o fundamento kantiano para a dignidade das pessoas é, paradoxalmente, "impessoal": "Se deve respeitar não o concreto ser humano, mas a abstração que está presente nele; não a dignidade da pessoa singular, mas a dignidade da lei moral; não o indivíduo específico, mas a humanidade em cada um”. 
É, em essência, a mesma crítica de Barroso (2012). Ou seja, que o sujeito kantiano não levaria em consideração os sentimentos, e seu valor seria pautado apenas na razão. No último parágrafo do mesmo tópico Sarmento (2016, p. 51) faz ainda mais um desenho do conceito de dignidade kantiana:

O ser humano, nessa perspectiva, continua a ser concebido como um fim em si mesmo, na linha de Kant. Mas não se trata mais de uma abstração racional, valiosa porque "tem a lei moral dentro de si", como queria Kant, mas sim de um indivíduo concreto, imerso num determinado universo material e simbólico, partícipe de uma teia de relações intersubjetivas que compõe a sua identidade. Uma pessoa real, que usa a razão e faz escolhas, mas que também sente fome, fica doente, cultiva amizades, ama, sofre precisa do outro, e que não deixa de ser digna por isso. Pelo contrário, essa humanidade "calorosa" - este "ser gente" - é uma das melhores justificativas para o reconhecimento da sua dignidade.

Sarmento (2016), mais a frente na argumentação da obra, assevera que o tipo de racionalidade iluminista, como a de Kant, diz respeito apenas ao homem, branco, burguês, que é capaz de agir com racionalidade. E não, a outros sujeitos que, no imaginário da época, teriam um tipo mais "emocional" de comportamento.

No campo da filosofia política, uma das críticas mais recentes a Kant foi a de Martha Nussbaum. Em Fronteiras da Justiça (2013), a norte-americana traça um conceito de dignidade que se fundamenta em uma concepção aristotélica e marxiana, em contraposição à ideia kantiana clássica. A argumentação que Nussbaum (2013) tem como base dois conceitos, já abordados anteriormente: racionalidade e animalidade.

A dignidade, pensada do ponto de vista kantiano, geralmente, é argumentada a partir dos conceitos de humanidade e personalidade, pelas razões que já foram expostas no tópico anterior. O grande problema, para Nussbaum (2013) é que esses conceitos se referem às capacidades racionais dos seres humanos, em contraposição às necessidades empíricas. A autora argumenta, ao contrário, que a racionalidade é apenas mais um dos elementos da animalidade e que apesar daquele conceito ser, de fato, um dos que distingue o homem dentro de uma lógica natural, ele não deve ser considerado como o único.

Segundo Nussbaum (2013) a sociabilidade e a noção de cuidado também integram a racionalidade e não são conceitos estanques. A racionalidade aumenta e declina com o tempo e a sociabilidade também envolve relações de assimetria e desigualdade, que não são levadas 
em consideração por um ideal de dignidade que se fundamenta apenas em uma concepção de produtividade a partir da razão.

A filosofia que Nussbaum (2013) prega é, em termos gerais, a de uma ética do cuidado. Esse tipo de concepção tem como um dos focos, justamente, contrapor-se à ideia de autonomia kantiana, vez que esse conceito exclui uma série de relações que não necessariamente são abarcadas pelo conceito de racionalidade construído pelo iluminista. Assim, a ética do cuidado também rejeita a noção kantiana de moralidade, em especial, por considerar que essa não abarca pontos centrais da vivência humana, como a proximidade de certas relações, permeadas por sentimentos e desejos. Em suma, nas palavras de um outro autor que coadua com essa ideia:

Ao construir a razão como rota para a autonomia moral, a concepções kantianas não deixam espaço para emoções como ingredientes legítimos do entendimento moral. Mesmo assim, uma agente moral certamente compreende a si e a sua situação entendendo o significado das suas reações emocionais. Ela também pode entender como isso ocorre com os outros primeiro simpatizando com eles em reação aos seus apuros. Se nos faltarem recursos para sensibilidade emocional em relação aos sentimentos e atitudes para outras pessoas, então será difícil, se não impossível, para nós desenvolvermos uma preocupação profunda pela sua situação moral. A teoria kantiana negligencia também a natureza interpessoal do raciocínio moral. O entendimento moral, como qualquer tipo de entendimento humano, é uma empreitada conjunta pela comunidade de indivíduos que se comunicam uns com os outros e compartilham práticas sociais. Em vez da conquista isolada sugerida pela teoria original de Kant, o raciocínio moral é fundamentado na vida social. (FRIEDMAN, 2006, p. 212/213, tradução nossa).

Assim, a dignidade passa a ser vislumbrada como um conceito que não abarca tão somente a racionalidade dos indivíduos, mas também leva em consideração elementos mais sensíveis, considerando o papel das emoções para a construção deste conceito. Porém a reconstrução da dignidade aqui proposta parte de um autor que utiliza conceitos kantianos para tanto, o qual será descrito nos tópicos que se seguem.

\section{DIGNIDADE E PRECEITOS ÉTICOS}

Dworkin (2011) considera os termos "ética" e "moralidade" no que ele alega ser um sentido diferente do usual: a ética trata questões sobre como viver bem e se preocupa com os objetivos de vida de cada indivíduo. A moralidade, de outro norte, trata sobre os deveres em 
relação aos outros. A moralidade, por seu turno, está dividida em moralidade pessoal e institucional. Enquanto a moralidade pessoal ou moral se relaciona com obrigações entre duas pessoas, como, e.g., no caso de uma promessa, a moralidade institucional ou política compreende a justificação das obrigações feitas em nome da comunidade para os indivíduos.

É uma integração entre os pressupostos éticos e morais (moralidade) que Dworkin (2011) busca. Para isso ele começa a sua teoria com a diferenciação de dois conceitos: o de vida boa e o de viver bem. Viver bem, argumenta o autor, inclui o conceito de vida boa, mas confere a este um caráter mais crítico que não o torna subjetivo às preferências de cada indivíduo. Isso não inclui, contudo, o objetivo de sempre realizar aquelas escolhas que melhor levarão a uma vida boa.

Uma pessoa pode ter uma vida boa, mas construi-la sobre traições e matanças e, portanto, falhar em viver bem. É por isso que esta noção, dentro da teoria de Dworkin (2011) é fundamental e o autor considera irresponsável viver tendo em mente apenas levar uma vida boa. Isso retoma ao conceito de responsabilidade moral que Dworkin (2011) abordou anteriormente na obra. Como não há como provar que os fatos morais são partículas independentes existentes no mundo, mas mesmo assim é necessário que existam verdades desse tipo, então, é preciso imputar uma responsabilidade moral ao sujeito.

Mas somente a noção de viver bem não é capaz de promover uma integração completa entre moralidade e ética. Para isso Dworkin (2011) propõe dois conceitos que dão conta dessa tarefa e que são nuclerares na sua concepção de dignidade: autenticidade e autorrespeito, ou respeito pela própria vida.

O primeiro princípio exige que o sujeito, e o foco aqui é apenas o sujeito em si, reconheça que viver bem tem um valor objetivo para si, ou seja, que se importe com a sua própria vida. E isso é contrário tanto a uma noção de escolha de projetos de vida aleatórios, porque isso impediria a existência de atitudes críticas por parte do sujeito, quanto de uma vida baseada apenas em prazer, porque isso exige uma reflexão sobre o que é prazer.

O segundo princípio ético, o da autenticidade, funciona como um outro lado do autorrespeito. Para Dworkin (2011), considerar seriamente a forma como se vive bem implica um julgamento de como se expressar na vida. Isso não significa, necessariamente, viver de uma forma completamente diferente de outra pessoa, mas sim de acordo com a situação e os valores que os sujeitos tomem por apropriados. Uma vida, portanto, severamente limitada pelas circunstâncias (pobreza ou algum tipo de doença), não será uma vida em desacordo com 
o princípio da dignidade se, entre as opções que foram proporcionadas, o sujeito conseguir escolher de forma crítica.

Isso também parte de um ideal de independência ética que pressupõe a possibilidade de levar a vida escolhida entre os tipos de vida que podem ser vividos em um determinado contexto, mas sem deixar que este determine absolutamente as escolhas do indivíduo. $\mathrm{O}$ princípio da autenticidade também pressupõe uma noção de responsabilidade enquanto virtude e, ocasionalmente enquanto relação. Por isso, a dignidade não permite que terceiros sejam culpados pela escolha do indivíduo (DWORKIN, 2011).

\section{A ÉTICA E O DEVER PARA COM OS OUTROS}

Na parte quarta da obra em estudo, o que Dworkin (2011) irá buscar é demonstrar como os princípios do autorrespeito e da autenticidade são relevantes para demonstrar o porquê de seguirmos a lei moral. É nesse ponto do livro que a teoria de Kant terá mais destaque. A argumentação tem início pelo primeiro princípio da dignidade. $\mathrm{O}$ autorrespeito, dirá o autor, deve ser concebido a partir da ótica do "princípio de Kant”:

Esse princípio sustenta que uma forma correta de autorrespeito - o autorrespeito demandado pelo primeiro princípio da dignidade - acarreta, em paralelo, um respeito pela vida de todos os seres humanos. Se você se respeita, então você precisa tratar a vida dos demais, também, como tendo uma importância objetiva. (DWORKIN, 2011, p. 254, tradução nossa).

Para explicar os limites de tal princípio, Dworkin (2011) questiona se o valor da vida de um indivíduo tem importância universal, ou seja, um valor em si, porque se trata de uma vida humana, ou se a importância é apenas circunstancial em virtude de alguma propriedade específica. Para o autor, negar que qualquer vida possui valor objetivo ou que uma responsabilidade especial pela própria vida produz tal valor, não são razões suficientes para acreditar na última hipótese. No primeiro caso, porque o sujeito valora a sua própria vida como objetiva, então não é possível alegar tal espécie de ceticismo. No segundo caso, porque da responsabilidade por algo específico não se infere que não exista um reconhecimento do valor das demais coisas (DWORKIN, 2011).

Outro argumento geralmente utilizado para essa diferenciação de valor é o de que determinadas vidas humanas possuem valor objetivo por certas propriedades que possuem. 
Essas características distintivas servem como um parâmetro para identificar a importância objetiva em viver bem. Isso não é possível de ser argumentado em um sistema muito amplo de valores vez que não é compatível com questões históricas ou econômicas, por exemplo (DWORKIN, 2011).

Também não é intuitivo, do ponto de vista da responsabilidade ética, argumentar que a vida só possui valor em relação a certos tipos de propriedade. Deve haver um equilíbrio entre o respeito por reconhecimento e por valor (DWORKIN, 2011).

O princípio kantiano gera, então, uma espécie de espelhamento. Porque a minha vida possui um valor objetivo, então, a vida de todos os outros seres racionais também possui:

O primeiro princípio da dignidade, repensado para tornar evidente o valor objetivo de qualquer vida humana, torna-se o que eu chamei de princípio de Kant. A sua razão para pensar como objetivamente importante como a sua vida vai é também uma razão para considerar importante como a vida de todas as outras pessoas vai: você vê a importância objetiva da sua vida espelhada na importância objetiva da vida de todos os outros. (DWORKIN, 2011, p. 260, tradução nossa).

Nesse ponto, Dworkin (2011, p. 260) formula a questão que será respondida no restante do livro, ou seja, quais são as implicações do princípio de Kant para como você deve tratar as outras pessoas? No tópico em comento Dworkin limita-se em tratar do desafio de considerar a importância objetiva que a vida traz.

Caso esse princípio seja adotado, ele diz, então, seríamos tentados a aceitar que os objetivos de todo mundo deveriam ser tão importantes quanto os nossos. Acontece que isso não é possível considerando a exigência do princípio da autenticidade. Isso não seria alcançável por um ponto neutro, vez que inexiste um ponto arquimediano para fora das próprias práticas sociais. Além disso, não há porque supor que as pessoas abandonariam a sua posição em função da perspectiva da situação dos outros, e se algum princípio nesse sentido fosse aceito, provavelmente geraria desvantagens absurdas para ambos os lados (DWORKIN, 2011).

O resultado é diferente, contudo, caso se leve em consideração os dois princípios da dignidade. Não há razão para escolher entre duas perspectivas, ou seja, a do autorrespeito e a da autenticidade, porque a interpretação dos dois princípios deve ser pautada em uma integração mútua, de forma que não haja contradição. Isso se coaduna com o restante do projeto de Dworkin (2011), que busca uma interpretação dos dois conceitos que dê suporte à 
interpretação dos demais e que pareça correta, defendendo, assim, um critério holístico para o julgamento de teorias políticas e jurídicas.

\subsection{O PROJETO KANTIANO DO PONTO DE VISTA HOLÍSTICO.}

Ainda no capítulo 11 Dworkin (2011) faz uma breve exegese das ideias de Rawls, Kant e Scanlon. Neste artigo, o foco será na exegese da teoria kantiana, dado o seu objeto de estudo. Dworkin (2011) começa o tópico sobre Kant afirmando que ele concorda com os princípios gerais que o iluminista formula, mas discorda de seus fundamentos de razão e liberdade. A leitura que o autor faz do projeto kantiano tem início na ética, porque essa seara é mais relevante para entender esse projeto de forma interpretativa. Ele argumenta que certos ditames éticos na filosofia de Kant contêm seus dois princípios de dignidade. O princípio da humanidade que Kant formula, diz Dworkin (2013, p. 265, tradução nossa)

É em primeira instância sobre o modo pelo qual nós devemos valorar a nós e aos nossos objetivos: devemos vê-los como objetivamente, não subjetivamente, importantes. Nós devemos pensar, como o nosso primeiro princípio insiste, que é objetivamente importante como as nossas vidas estão sendo vividas.

A partir desse princípio é que Dworkin (2011) vai concluir que a humanidade é o valor objetivo da vida e isso conduz a um espelhamento que obriga um determinado tipo de tratamento em relação à vida das outras pessoas. O autorrespeito, primeiro princípio da dignidade, impõe tanto que as outras pessoas sejam tratadas como objetivamente importantes, como que o sujeito seja autônomo, ou seja, que possa estruturar as suas convicções de vida. Esse último ditame leva ao segundo princípio da dignidade, o da autenticidade, que demanda um julgamento sobre o melhor modo de viver de acordo com uma postura crítica.

Não há como a filosofia prática de Kant resolver as demandas provenientes dos dois ditames da dignidade e que Dworkin (2011) já expôs anteriormente. Isso geraria um sacrifício de algum dos princípios e, portanto, da dignidade. Na leitura de Dworkin (2011), o que o iluminista faz é interpretar o melhor das duas demandas que a dignidade impõe. A autonomia não será a total liberdade para escolher entre qualquer inclinação, mas, sim, a liberdade das inclinações, em oposição à heteronomia. O sujeito autônomo, em Kant, será aquele que leva em consideração a lei moral como ditame para as suas ações, e não objetivos pessoais. Ao 
tratar as nossas próprias ações de forma paralela a qualquer tipo de inclinação, estamos tratando da nossa vida e o modo como devemos viver como um fim, e portanto, algo como valor objetivo, e não meramente como um meio (DWORKIN, 2011). Isso, em Kant (2009), não significa fazer as coisas apenas conforme o dever, mas pelo dever.

A noção de autonomia kantiana, segundo Dworkin (2011), é convergente com a de responsabilidade que ele apresentou no capítulo 6 do livro. Segundo o autor, esse conceito também não leva em consideração as influências da história pessoal de cada um.

Mas isso não responde à pergunta de como devemos tratar os outros. A autonomia kantiana, nos moldes como Dworkin (2011) a descreve, diria respeito apenas à ética, e não também à moral. Mas dessa descrição de autonomia não se infere que o sujeito deva agir de forma imparcial.

Ele oferece uma forma de universalismo diferente e muito menos exigente: nós devemos agir de tal modo que possamos desejar que o princípio da nossa ação seja universalmente abraçado e seguido. Uma pessoa respeita o seu próprio valor ético intrínseco através de tal princípio porque, como Kant coloca: "é precisamente a aptidão das suas máximas para se tornarem lei universal que o marca como fim em si mesmo." (DWORKIN, 2011, p. 266, tradução nossa).

Apesar das divergências de interpretação desta fórmula kantiana, Dworkin (2011) diz que seu pressuposto é bastante claro: tratar as pessoas com o respeito que reputamos a nós mesmos é considerar que nenhum direito é válido para os outros, sem que também o seja para nós e vice-versa.

A fórmula kantiana, do modo como foi expressa, contudo, poderia fazer a argumentação recair em um problema que já foi apontado: a igualdade de preocupação entre os fins do próprio sujeito e dos demais indivíduos. Dworkin (2011) argumenta, contudo, que a teoria kantiana é pensada de tal modo que seus exemplos reformulam a moralidade prática, produzindo deveres que, universalizados, acabam sendo familiares.

A ligação de Dworkin (2011) realiza entre ética e moralidade em Kant e a sua leitura do projeto do iluminista tem como escopo, portanto, tornar mais interessantes seus argumentos. Dworkin (2011) argumenta que apesar de Kant não supor que agir de acordo com a lei moral possa produzir a vida boa, ele supõe que isso geraria um viver bem, com autorrespeito e autonomia, gerando um sistema de holismo ativo. 


\section{A LEITURA DO OURIÇO DESCREVE MELHOR O SISTEMA KANTIANO?}

O que Dworkin (2011) faz, na sua tentativa de reconstruir o sistema moral kantiano é exatamente se contrapor àquela leitura que Barroso (2012) imputa a Hume e a Hegel, bem como às críticas que ele mesmo faz à dignidade kantiana. Na leitura de Dworkin (2011), o ser humano não ignora completamente os seus desejos, mas apenas coloca-os dentro de determinados limites éticos, que influenciam diretamente no seu projeto de moralidade.

Ao reconstruir o conceito kantiano de autonomia, o que Dworkin (2011) faz é interligar essa noção aos dois princípios da dignidade que ele formulou no campo da ética. Assim, a forma mais completa de se pensar a autenticidade e o autorrespeito é aquela a partir do princípio de Kant.

Assim, essa nova versão da moralidade kantiana não apenas considera os desejos dos indivíduos como relevantes, mas também parte da sua necessidade de consideração, contida no princípio do autorrespeito, para determinar os deveres para com os outros.

Ao delimitar o preceito ético da autenticidade, o que Dworkin (2011) faz também é limitar as escolhas que o sujeito faz dentro da noção de dignidade às possibilidades fáticas que lhes estão disponíveis. Assim, quando os ditames da dignidade passam da esfera da ética para a moralidade e ganham contornos kantianos, Dworkin (2011) já está pressupondo que há necessidade de considerar as formas de vida que estão disponíveis no seio social e que são valiosas de serem vividas.

O mesmo pode ser dito da crítica de Sarmento (2016) ao individualismo normativo kantiano. Em Dworkin (2011), apesar do valor do ser humano continuar com seu caráter universal, ele se liga a projetos mais concretos, dentro das escolhas de vida de cada indivíduo. A razão continua como guia, porque os projetos de vida de cada um não podem ser escolhidos com base em desejos empíricos ou de forma aleatória, mas o que é importante para cada um é valorizado. E isso afeta como nós devemos valorizar os projetos dos outros seres humanos.

O valor do ser humano passa a ser não mais somente a autonomia enquanto uma das formulações do imperativo categórico, mas a autonomia enquanto liberdade. Assim, o valor de cada um de acordo com o princípio kantiano não se liga mais necessariamente à lei moral, e sim, ao projeto que cada indivíduo possui para a sua vida, bem como à responsabilidade ética em cada um. 
A crítica de Nussbaum (2013), pautada na ética do cuidado, em parte também é abarcada pela reformulação de Dworkin (2011). Ele consegue reformular a teoria de Kant de forma que ela também influencia na maneira como os indivíduos prestam auxílio uns para os outros. A interação entre os seres humanos, como já foi tratado, também ocorre na medida em que a dignidade se liga à consideração objetiva dos projetos dos outros.

Contudo, um ponto é deixado de fora pela abordagem de Dworkin (2011): a diferença, que Nussbaum (2013) ressalta entre as diferentes capacidades dos indivíduos. ${ }^{9}$ Apesar de Dworkin (2011) tornar como essencial a possibilidade de escolha do modo de vida a ser vivido, ainda sim ele desconsidera determinados tipos de existências que são tão severamente limitados que o indivíduo não consegue realizar tal atividade.

O ponto central dessa crítica de Nussbaum pode ser compreendido pelo exemplo, trazido pelo próprio Dworkin, para compreender a sua teoria igualitarista. Dworkin (2011, p. 287-288) compara o campo do discurso prático com uma piscina com raias delimitando os espaços, nos quais cada indivíduo pode nadar. ${ }^{10}$ Dentro das suas raias, o modo como cada um decide nadar para alcançar o seu objetivo não pode ser controlado por ninguém, dado que isso seria uma violação do igual respeito e consideração pela vida de cada um. Este é o campo da ética ou do viver bem, conforme acima discutido.

Em contrapartida, caso um indivíduo da raia ao lado necessite de algum auxílio, por exemplo, em caso de afogamento, ou caso uma nadadora cause danos a outra durante o seu nado, há, nestes casos, uma obrigação por parte das nadadoras entre si. Este é o campo da moralidade pessoal ou moral. Por fim, para que cada indivíduo possa alcançar os seus objetivos por meio da escolha do seu modo de nadar, é importante que a todos e todas sejam distribuídas iguais recursos, o que, em última instância, corresponde ao campo da política.

A referida crítica a Dworkin no contexto dessa metáfora consiste na carência de preocupação com fatores sociais que limitam a possibilidade de escolha das nadadoras. $\mathrm{Ou}$ seja, em muitos casos, a mera oferta ou distribuição de recursos não é suficiente para possibilitar aos indivíduos, de fato, o exercício da sua autonomia, devendo a sociedade se preocupar com outras dimensões da vida social, como, e.g., a formação da identidade,

\footnotetext{
${ }^{9}$ É interessante notar que o mesmo ponto já foi objeto do debate entre Rawls e Sen. Acerca disso: DWORKIN, 2011, p. 352.

10 "Nós vivemos nossas vidas, normalmente, em raias demarcadas e separadas. (...) Porém, cada pessoa pode se concentrar em nadar a sua própria competição sem preocupação com o fato de que, se ele, de fato, vencer, então, outra pessoas precisa perder." (DWORKIN, 2011, p. 287-288; trad. nossa).
} 
conceções sobre formas de vida ou a valoração econômica de determinadas funções na sociedade.

O caso das pessoas com deficiência (física ou mental) é significativo para compreender esse ponto, tendo em vista que, nestes casos, a própria possibilidade de nadar pode ser extremamente limitada ou, até mesmo, impossível. Em outros casos, como, e.g., o dos indígenas, poderá haver desacordo até mesmo sobre o objetivo da prática da natação, dados certos pressupostos da forma de vida adotada por determinadas comunidades indígenas.

Há duas respostas possíveis de Dworkin a esse ponto: (a) a primeira consiste em negar que o seu argumento se baseia, tal qual em Kant, em um sujeito transcendental; e (b) a segunda compreende a tese de que a crítica de Nussbaum culminaria, possivelmente, em um desrespeito ao princípio da independência ética, sendo, logo, uma violação à dignidade no âmbito da moralidade institucional ou política.

A um, Dworkin (2011, p. 1) parece ter consciência dessas limitações de sua teoria, quando, no início da obra, afirma que a sua concepção de dignidade pressupõe um determinado modo de vida (way of life). Posteriormente, no mesmo sentido, Dworkin (2011, p. 14) reafirma tal ideia ao dizer que uma resposta à pergunta socrática "Por que ser moral?" deve iniciar pela questão acerca de como devemos ser responsáveis pela apelo da moralidade que já sentimos. Ele rejeita, portanto, desde a introdução do livro, a ideia de que a sua teoria pressupõe uma metafísica no sentido de um sujeito transcendental, independente da própria prática social.

De um lado, essa assertiva parecer compreender a negação da tentativa de fundamentar valores com base em características pertencentes ao agente individual, como era a estratégia na Antiguidade, sobretudo, em Platão. Para estas teorias o que é, em primeiro lugar, eticamente desejável precisa ser algo que se encontra no próprio agente. Se o fundamento da ética estiver fora da alma como, por exemplo, em uma instituição ou prática social, então, haverá sempre a possibilidade de uma pessoa, em virtude do seu estado da alma, não agir em consonância com a instituição e, por conseguinte, não agir de modo favorável à realização de uma vida ética. A estratégia de Dworkin (2011), ao contrário, consiste em defender uma teoria dos valores sem cair nos erros de teorias da Antiguidade, que pressupõem, em última instância, interesses reais ou essenciais do ser humano racional, sem lidar com problemas decorrentes de uma análise das práticas sociais. 
Por outro lado, a assertiva de que a sua teoria dos valores é um modo de vida compreende a ideia de que os valores não podem ser demonstrados como fatos simples, descritivos ou brutos. Dessa forma, os argumentos no campo da moralidade são fatos normativos ou complexos, pois sempre envolvem, de um lado, ações particulares e, por outro lado, valores que lhes conferem significado social. Os fatos normativos ou complexos são formados pela compreensão dessas duas dimensões, intrinsicamente, vinculadas.

Não obstante, permanece ainda obscuro compreender por que devemos aceitar o modo de vida, pressuposto pela concepção de dignidade de Dworkin, pelo simples fato de ele conseguir articular de modo mais abrangente e coerente um sistema de valores, comumente, aceitos em sociedade liberais e democráticas, mesmo que tal articulação signifique ignorar outras formas de vida existentes nessas mesmas sociedades.

A dois, uma outra resposta de Dworkin a esse questionamento consiste na ideia de que, qualquer tentativa de atividade política de questões relacionadas com identidade ou proteção a determinadas formas de vida pode resultar em uma violação ao princípio da independência ética, ou seja, a ideia de que cada indivíduo tem o direito de decidir sobre como irá buscar a vida boa. Ademais, mesmo que o argumento de Nussbaum não resulte em uma violação à independência ética, ele ainda poderia estar inserido na crítica de Dworkin a Sen no sentido de que a sua teoria não apresenta critérios específicos para definir o que deve ser feito nos casos fronteiriços citados acima, a dizer, quais capacidades devem ser privilegiadas em caso de desacordos sérios (DWORKIN, 2011, nota 3, p. 477). ${ }^{11}$

\section{CONSIDERAÇÕES FINAIS}

O presente artigo partiu da noção de dignidade, considerando, em seu núcleo mínimo, o valor absoluto dos seres humanos. Esse conceito foi tratado dentro da filosofia kantiana, vez que essa figura como uma das principais formulações dessa ideia, dentro de uma visão cronológica do conceito. Dentro da teoria kantiana de dignidade, foram tratadas as noções de autonomia e humanidade, centrais para o desenvolvimento do conceito a partir do autor trabalhado.

\footnotetext{
${ }^{11}$ Por não ser objeto deste estudo, não será possível aprofundar esse ponto. Porém, Nussbaum, mais recentemente, adota critérios específicos para estabelecer um ranking entre as capacidades, respondendo, portanto, às críticas de Dworkin à obra de Sen. Acerca disso: NUSSBAUM, 2011, p. 44.
} 
Após, a crítica ao conceito extremamente racionalista de sujeito da ética kantiana foi abordada tanto do ponto de vista da formulação jurídica do conceito de dignidade, quanto da visão de uma ética do cuidado. Do primeiro ponto de vista, a crítica trata da noção de um sujeito abstrato, que não leva em consideração desejos empíricos. Por seu turno, a crítica do ponto de vista da ética do cuidado é pautada, principalmente, no fato de que a abstração do sujeito kantiano e a prevalência da racionalidade sobre outras capacidades gera uma impossibilidade de considerar outros pontos da interação humana, como o cuidado com os outros e a sociabilidade.

Em relação à teoria de Dworkin (2011), foram abordados os seus conceitos morais e éticos a partir da autenticidade e do autorrespeito. Também, foi feita uma descrição detalhada da forma como Dworkin (2011) interpreta Kant, e o do modo como ele o utiliza para integrar ética e moralidade.

Em seguida, a exposição da teoria dworkiniana foi analisada à luz da crítica a Kant. A resposta que se chegou foi a de que a reformulação da teoria moral de Kant, realizada por Dworkin (2011), e a forma como ele liga a noção de valor do ser humano às ideias de autenticidade e autorrespeito, de fato, é capaz de superar alguns pontos das críticas que são feitas a Kant, mas ainda deixa algumas brechas, como, e.g., em relação àqueles e àquelas que não possuem condições de realizar escolhas racionais do nível exigido pela teoria.

Isso porque a teoria de Dworkin (2011) exige que os seres humanos sejam capazes de, em alguma medida, proceder com escolhas racionais de projetos de vida, que tenham algum valor e esses projetos de vida têm que ser, em certo sentido, autênticos. Isso excluiria por exemplo, pessoas com limitações físicas tão severas que não seriam capazes de formular tais tipos de raciocínio. Nesse sentido, a conclusão do trabalho aponta para obscuridade quanto ao critério de escolha de um modo de vida específico, pressuposto pela concepção de dignidade em Dworkin.

\section{REFERÊNCIAS:}

ABBAGNANO, Nicola. Dicionário de filosofia. São Paulo: Martins Fontes, 2007.

BARROSO, Luís Roberto. A Dignidade da Pessoa Humana no Direito Constitucional

Contemporâneo: Construção de um Conceito Jurídico à Luz da Jurisprudência Mundial. Belo Horizonte: Fórum, 2012. 
BRUGGER, Winfried. Liberalismus, Pluralismus, Kommunitarismus: Studien zur Legitimation des Grundgesetzes. Baden-Baden: Nomos, 1999.

DWORKIN, Ronald. Justice for Hedgehogs. Cambridge: The Belknap Press of Harvard University Press, 2011.

A Raposa e o Porco-Espinho: Justiça e Valor. Tradução Marcelo Brandão Cipolla. São Paulo: WMF Martins Fontes, 2014.

Law's Empire. Cambridge, Mass.: Belknap Press, 1986.

ELEFTHERIADIS, Pavlos. Legal Rights. Oxford: Oxford University Press, 2008.

FORMOSA, Paul. Dignity and Respect: How to Apply Kant's Formula of Humanity. Philosophical Forum, vol. 45, n. 1, pp. 49-68, 2014.

FRIEDMAN, Marilyn. Feminism in ethics: conceptions of automony. In: FRICKER, Miranda; HORNSBY, Jennifer (Org.). Cambridge Companion to Feminism in Philosophy. Cambridge: Cambridge University Press, 2006.

GREENBERG, Mark. How facts make law. Legal Theory, vol. 10, p. 157-98, 2004.

HONNETH, Axel. O Direito da Liberdade. Trad. de Saulo Krieger. Martins Fontes: São Paulo, 2015.

KANT, Immanuel. Fundamentação da Metafísica dos Costumes. Tradução, introdução e notas de Guido Antônio de Almeida. São Paulo: Discurso Editorial; São Paulo: Barcarolla, 2009.

MCCRUDDEN, Christopher. Human dignity and judicial interpretation of human rights. European Journal of International Law, Firenze. v. 19, n4, p. 655-724, 2008.

NUSSBAUM, Martha. Creating capabilities: the human development approach. Cambridge (Mass.): Harvard University Press, 2011.

Fronteiras da Justiça: Deficiência, Nacionalidade, Pertencimento à Espécie.

Tradução Susana de Castro. São Paulo: WMF Martins Fontes, 2013.

PFORDTEN, Dietmar v. d. Menschenwürde, Recht und Staat bei Kant: fünf Untersuchungen. Paderborn: Mentis, 2009.

SARMENTO, Daniel. Dignidade da Pessoa Humana: conteúdo, trajetórias e metodologia. 2 ed. Belo Horizonte: Fórum, 2016

WOOD, Allen. Kantian Ethics. New York: Cambridge University Press, 2008. 